\title{
ONTOLOGIA DA PRODUÇÃO DO ESPAÇO NA GEOGRAFIA: UMA ABORDAGEM DO TEMA ATRAVES DO DIALOGO ENTRE MILTON SANTOS E HEIDEGGER SOBRE A TÉCNICA
}

Ontology of Production of Space in Geography: an Approach of the theme Through Dialogue between Milton Santos and Heidegger About the Technique

Ontogía de la PRoduccíon del Espacio en Geografia: un Enfoque del Tema por el Diálogo entre Milton Santos y Heidegger sobre la Técnica

Luis Carlos Tosta dos Reis

Professor no Departamento de Geografia e

PPGG da UFES

e-mail: Ictosta.reis@gmail.com

\section{Resumo}

O artigo objetiva prestar uma contribuição ao tema da ontologia do espaço na geografia problematizando-o através do paralelo entre, por um lado, o pensamento de Milton Santos acerca da relação entre técnica e ontologia do espaço e; por outro lado, o pensamento de cunho ontológico que o filósofo Martin Heidegger desenvolveu a partir de sua peculiar posição diante da questão da técnica. Essa perspectiva de problematização é proposta na medida em que permite articular a convergência de noções fundamentais ao debate teórico sobre a ontologia do espaço na geografia, quais sejam: a produção (social) do espaço; a técnica; e o tema primordial de toda investigação ontológica, o ser.

Palavras-Chave: Ontologia; Espaço; Técnica. 


\section{Abstract}

The paper aims to provide a contribution to the theme of the ontology of space in geography questioning him through the parallel between, on the one hand, the thought of Milton Santos about the relationship between art and ontology space and, on the other hand, the thought of stamp the ontological philosopher Martin Heidegger developed from its peculiar position on the question of technique. This approach is proposed because allows articulate the fundamental notions to the theoretical debate about the ontology of space in geography, namely: production (social) space, the technique, and the major issue theme of the entire investigation ontological, the being.

Keywords: Ontology; Space; Technique.

\section{Resumen}

El artículo tiene como objetivo proporcionar una contribución al tema de la ontología del espacio en la geografía preguntarle por el paralelo entre, por un lado, el pensamiento de Milton Santos acerca de la relación entre technique y ontología del espacio y, por otro lado, la naturaleza ontológica del pensamiento que el filósofo Martin Heidegger desarrolló a partir de su peculiar posición sobre la cuestión de la técnica. Esta perspectiva permite articular las nociones fundamentales de convergencia para el debate teórico acerca de la ontología del espacio en la geografía, a saber: la producción (social) de espacio, la técnica y el tema general de la investigación ontológica, el ser.

Palabras clave: Ontología; Espacio; Technique.

\section{Résumé}

Cet article vise à fournir une contribution sur le thème de l'ontologie de l'espace en géographie en le problématisant à travers le parallèle entre, d'une part, la pensée de Milton Santos à propos de la relation entre la technique et ontologie de l'espace et, d'autre part, la pensée de nature ontologique que le philosophe Martin Heidegger a développée à partir de sa position particulière sur la question de la technique. Cette perspective de problématisation est proposé dans la mesure où elle permet d'articuler la convergence des notions fondamentales vers le débat théorique sur l'ontologie de l'espace en géographie, à savoir: la production de l'espace (social), la technique, et le thème principal de toute I'enquête ontologique, l'être.

Mots-clés: Ontologie; Espace; Technique. 


\section{INTRODUÇÃO}

O presente texto aborda o tema da ontologia do espaço em geografia. Mais especificamente visa às possibilidades que a convergência temática entre ontologia e técnica, de acordo com a perspectiva que será delineada no que segue, oferece à problematização ontológica do espaço nesta disciplina ${ }^{1}$.

$O$ viés de problematização aqui assumido orienta-se no sentido de estabelecer um paralelo entre dois caminhos de pensamento que articulam técnica e ontologia, quais sejam: por um lado, o viés proposto por Milton SANTOS (1996) que imputa à noção de técnica um significado central à elaboração da ontologia do espaço; e, por outro lado, no plano mais estrito da ontologia - leia-se, a rigor, da

$1 \quad$ O artigo constitui uma continuação direta de um trabalho precedente intitulado "Ontologia do Espaço e Movimento de Renovação Crítica da Geografia: o desafio da diferença ontológica" (REIS, 2009), cujas considerações finais sinalizaram para as possibilidades de desenvolver uma reflexão sobre o assunto através de sua articulação com o pensamento de Martin Heidegger sobre a questão da técnica. questão acerca do sentido do ser - recorre-se à questão da técnica tal como formulada por Martin Heidegger, cuja contribuição resguarda co-pertinência entre a técnica e o assunto de toda investigação ontológica, a saber, o ser.

Se entre os geógrafos a contribuição de Milton Santos ao tema dispensa apresentações, caberia dimensionar a envergadura da problematização ontológica da técnica em Heidegger, pois, para não poucos estudiosos do assunto, "ninguém abordou, tanto quanto ele, o problema da 'essência' do mundo técnico; isto é, Heidegger foi, sem dúvida, o pensador que mais longe foi na perspectiva ontológica da abordagem da técnica"(CRAIA, 2003:72)2. O paralelo proposto entre o geógrafo e o filósofo não é, portanto, fortuito. Ele sinaliza,

\footnotetext{
2 A "obra" de Heidegger é integralmente dedicada à elaboração do pensamento ontológico, isto é, à questão do ser. A envergadura da repercussão de sua obra sobre o assunto inscreve-se no seio de um diálogo profundo com a tradição do pensamento filosófico ocidental e, assim, somente a partir de um quadro de referência que permitisse minimamente situar o significado do pensamento filosófico, enquanto tal, para a história ocidental-européia, permitiria "aquilatar", com propriedade - fosse essa uma demanda passível de ser considerada legítima - a influência e o alcance de seu pensamento. Isso, evidentemente, excede as possibilidades do presente artigo.
} 
sobretudo, que a assimilação do pensamento deste filósofo é entrevista como sendo capaz ampliar o escopo da reflexão sobre ontologia na geografia, na medida em que permitiria radicalizar os traços fundamentais desta reflexão, conduzindo-os para uma esfera de elaboração que, exclusivamente a partir deles próprios, permaneceria latente no debate teórico desta disciplina.

Assim, a copertinência temática - ainda que estritamente formal - entre os dois autores é evidente, pois, em ambos a técnica é abordada sob uma perspectiva ontológica. Entretanto, é relevante desde já observar, o escopo da reflexão é essencialmente distinto em cada autor: enquanto em Milton Santos a técnica constitui elemento fundamental à elaboração de uma ontologia do espaço tecida sob a expectativa de prover orientação teórico-metodológica à geografia; em Heidegger a questão da técnica assinala uma alternativa de elaboração não-metafísica de pensar (o senti- do Ser). O sentido da questão da técnica no filosófo é, assim, relativamente mais obscuro e, certamente, mais distante daquele que, usualmente, encontra-se disponível nos limites do debate teórico de uma disciplina acadêmica, no caso, a geografia. Esclarecer o sentido desta questão e seu nexo com a problemática da ontologia do espaço na geografia constitui um atributo do desenvolvimento do presente trabalho.

Atentar para a diferença no escopo da reflexão em cada autor é importante, pois ela estabelece uma articulação prévia entre o pensamento do geógrafo e do filósofo. Dada a maior amplitude da questão da técnica em Heidegger, seu pensamento pode instaurar, sugere-se, uma autêntica reflexão acerca da concepção de técnica vigente na ontologia do espaço de Milton Santos. Isso se verifica, na medida em que, como será visto, o pensamento de Heidegger permitiria, sugere-se, desdobrar o fundamento desta concepção sobre si 
mesmo. Nesse sentido, no que segue, a exposição do perfil da abordagem e concepção da técnica em Milton Santos, e de seu significado para a ontologia do espaço na geografia irá preceder a apresentação do sentido ontológico da questão da técnica em Heidegger, consistindo, na parte principal do presente trabalho ${ }^{3}$.

3 Não há em Milton Santos uma preocupação de definição formal e cabal do "conceito de ontologia", sendo o significado por ele imputado ao termo delineado no bojo da própria elaboração de sua ontologia do espaço, fundamentalmente direcionada à apreensão da natureza do objeto da geografia - e das categorias necessárias para sua análise. No caso de Heidegger, como se sabe, toda a sua obra é dedicada à questão primordial da "ontologia", isto é, a questão do ser. Contudo, ao longo de sua vasta obra o modo com a qual o filósofo se referiu ao "rótulo" ontologia conheceu várias "modulações" tendo chegado, mesmo, a abandonar o "rótulo" ontologia em favor do que sempre se constitui, para além dos "rótulos", como o cerne de seu pensamento filosófico: a questão do ser. A passagem abaixo é, nesse sentido, ilustrativa: "O título 'ontologia' cunhou-se somente no século XVII. Designa a elaboração da doutrina tradicional do ente numa disciplina da filosofia e num membro do sistema filosófico. A doutrina tradicional, porém, é a análise e sistematização acadêmica do que, para Platão e Aristóteles e depois para Kant, constituía uma QUESTÃO, embora já não mais originária. Nesse sentido, ainda hoje, se emprega a palavra "Ontologia". Sob esse título a filosofia empreende cada vez mais a constituição e exposição de uma matéria dentro de seu sistema. A palavra "Ontologia" pode ser tomada também em 'sentido amplíssimo' 'sem referência a correntes e tendências ontológicas' (Cfr. Sein und Zeit, 1927, p.11). Nesse caso, 'ontologia' significa o esforço de traduzir em linguagem o Ser mas através da questão, o que há com o Ser (não apenas como o ente como tal). Até agora, porém, essa questão não encontrou repercussão nem, menos ainda, ressonância mas se viu, até mesmo, repelida expressamente pelos diversos círculos de eruditos da filosofia acadêmica, que se esforçam por uma ontologia em sentido tradicional. Por isso seria conveniente renunciar no futuro ao uso dos termos 'ontologia', 'ontológico'. Modos de investigação, separados entre si por todo um mundo, como só agora se constata com maior clareza, também não devem levar o mesmo nome" (Heidegger, M. Introdução à Metafísica. Ed. Tempo Brasileiro. Rio de Janeiro, 1999: p $67-68)$.
Antes, contudo, de abordar diretamente o cerne da reflexão, considera-se necessário trazer à tona, no tópico seguinte, algumas considerações preliminares, visando fornecer um esclarecimento mais panorâmico acerca da temática da ontologia do espaço na geografia, sobretudo porque constitui um assunto submetido a polêmicas que atingem a rejeição de sua própria legitimidade, como, além disso, não raro é depreciativamente considerado envolto sob uma aura de obscurantismo "especulativo-filosofante" que em nada favorece a apreensão da eventual contribuição que poderia oferecer ao debate teórico de uma disciplina.

\section{SOBRE ONTOLOGIA DO ESPAÇO NA GEOGRAFIA E O PROBLEMA DA ENTIFICAÇÃO SOCIAL DO SER}

A respeito da reflexão sobre a ontologia do espaço na geografia, dois atributos podem ser, a princípio, considerados constitutivos e, assim, destacados para viabilizar uma aproximação 
ao tema, quais sejam: por um lado, sua inequívoca presença no debate teórico atual da disciplina e; por outro lado, o caráter dilemático, polêmico (até mesmo ambíguo) que caracteriza o tratamento dispensado ao assunto nesse debate.

A presença da reflexão ontológica no debate teórico da geografia está longe de poder ser considerado residual, como evidencia o interesse que tem suscitado em contribuições recentes, dotadas de escopos os mais diversos em relação ao assunto (BESSE, 2011; HOLZER, 2010; 2011; 2012; MARANDOLA JR, 2011; 2012 BIBETI, 2007; PEDROSA, 2012; MOREIRA, 2004; 2007; 2012; REIS, 2009). Esses trabalhos atestam, a despeito de posições discordantes, a permanência do interesse sobre o assunto na geografia ao longo de quatro décadas, na medida em que a origem de sua abordagem temática remete à gênese do movimento de renovação crítica na década de 1970 (REIS, 2009). A permanência do inte- resse sobre o tema constituiria, a princípio, um sinal da relevância que a reflexão ontológica sobre o espaço teria assumido na geografia. Esse sinal, contudo, não significa ausência de polêmica em torno do assunto, nem, tampouco exclui posições que rejeitam abertamente a legitimidade da reflexão ontológica no debate teórico atual, tal como, por exemplo, atesta a citação abaixo:

\begin{abstract}
"Nesse momento crítico, a Geografia também permitiu que a preocupação com a construção de uma teoria geográfica conduzisse à busca da natureza ontológica do espaço como negação quase que total da dimensão real" (CARLOS, 2011: 146).
\end{abstract}

Em outra passagem da mesma obra, a reflexão ontológica é - a partir da posição da autora em relação ao pensamento de Marx - desqualificada na medida em que o pensamento marxista,

"(...) reclama o deslocamento da análise do plano da ontologia, e também do plano da epistemologia 
- prisioneiros do mundo abstrato das ideias - para aquele que articula a teoria (plano da produção do do) e a prática (práxis) em sua indicissociabilidade. (CARLOS, 2011: $26-27$ ).

Esta rejeição explícita é reiteradamente ratificada quando, na referida obra, a ontologia é considerada. A propósito, não só a legitimidade da ontologia do espaço é recusada, como também a própria possibilidade de sua elaboração, pois,

"(...) o espaço como momento da produção social encontra seu fundamento na construção/constituição da sociedade ao longo do processo histórico como constitutivo da humanidade do homem. Assim, não haveria leis do espaço, nem a possibilidade de uma ontologia do mesmo, posto que sua produção situa-se na totalidade do processo histórico como processo civilizatório, como realidade prática" (CARLOS, 2011: 17).

Trata-se de uma posição que coloca frontalmente em xeque a reflexão ontológica na $\frac{\text { geografia }{ }^{4} \text {. Cabe, assim, considerá-la de modo }}{4 \text { A tendência à rejeição à ontologia constitui, de fato, uma posição }}$ mais detido, na medida em que ela constringe diretamente a legitimidade de trabalhos dedicados ao tema.

A partir de um ângulo de consideração mais formal, poder-se-ia objetar que a posição assumida na citação acima não é, antes de tudo, consensual no seio do próprio pensamento marxista, como atestam os trabalhos dedicados à ontologia conduzida por marxistas, dentre os quais caberia destacar, por exemplo, uma obra da estatura de G. Lukács, bem como toda literatura sobre ontologia "marxista" derivada de sua ampla influência (CHASIN, 2009; LESSA, 2007), que envolve, a propósito, contribuições à elaboração da ontologia do espaço no seio da renovação crítica-marxista da geografia brasileira, levadas a cabo por Armando

muito recorrente no âmbito das perspectivas de elaboração teórica mais diretamente influenciadas pelo pensamento marxista, como diagnosticou Edward Soja ao problematizar o assunto: "Presumindo que restem poucas coisas importantes a descobrir no discurso ontológico, com seu característico distanciamento da praxis, a maioria dos marxistas ocidentais tem hesitado em se aventurar muito longe nesse caminho voltado para o passado. Mas trata-se de uma viagem que vale a pena fazer, pois pode ajudar-nos a descobrir algumas conexões que ainda faltam entre o espaço, o tempo e o ser e, por conseguinte, entre as feituras da história, da geografia humana e da sociedade" (SOJA, 1993:160). 
Correia da Silva, Ruy Moreira e Antonio Carlos Robert Morares. Além disso, é digno de nota que o significado de ontologia, no corpo da obra supracitada não pode ser deduzido senão de maneira residual e indireta, a propósito, através da desqualificação da ontologia como idealismo especulativo. Ora, seria passível imputar este predicado à obra de G. Lukács dedicada à ontologia? O mesmo predicado caberia a propósito dos trabalhos que se dedicaram a ontologia do espaço desenvolvidos por Milton Santos, Armando C. da Silva; Ruy Moreira, dentre outros autores que contribuíram para a renovação crítica sob forte influência, ainda que não exclusiva, do pensamento marxista?

Há, igualmente, um atributo passível de ser destacado como mais substantivo acerca da rejeição em relação à ontologia, do qual as citações acima são representativas: sua ambiguidade. Em sua forma mais evidente a ambiguidade se manifesta no modo com o qual, a despeito da recusa frontal à ontologia, a própria obra citada incida em inferências explícitas acerca do ser, assunto primordial da reflexão ontológica. Isso pode ser constatado na citação abaixo, quando a autora, ao tematizar a práxis sob as coordenadas do pensamento marxista indica que "(...) a natureza metarmorfoseia-se num conjunto de objetos ricos de sentidos, ao mesmo tempo em que vai se tornando mundo, como obra e manifestação da potência do ser" (CARLOS, 2011: $40)^{5}$. Ainda que, de fato, estas ilações explícitas ao ser constituam passagens residuais no corpo do trabalho citado, elas não deixam de incitar questões, tais como: o que se entende por ser nestas passagens? Se, contudo, para uma larga tradição do pensamento, o ser corresponde ao assunto primordial da ontologia e, por sua vez, esta é considerada uma "negação quase total da dimensão real", o quê, efetivamente, seria possível compreender acerca $5 \quad$ O mesmo se verifica quando a autora recorre à noção de produção em Lefbvre, que, a partir da tradição hegeliana "aponta a produção do ser enquanto ser genérico" (CARLOS, 2011: 49). 
da noção de ser empregada na citação acima? Não há, no referido trabalho, nenhuma consideração explicitativa a respeito da referida noção, o que, de resto, seria coerente com a rejeição assumida à ontologia. Isso, contudo, não anula a questão em aberto acerca do que significaria ser nas referidas passagens. Desta forma, excluindo a possibilidade de considerar o ser como "algo" auto-evidente, tratar-se-ia de uma compreensão pressuposta acerca do ser, tão evidente que dispensaria esclarecimento prévio ou ulterior.

Há, ainda, uma maneira menos direta de se evidenciar a ambiguidade inerente às posições contrárias à possibilidade da reflexão ontológica, qual seja, o fato de que mesmo a rejeição à ontologia implicar, ainda que a sua revelia, em juízos de natureza ontológica. Tal como foi observado, as citações destacadas refutam a ontologia considerando-a prisioneira do mundo abstrato das ideias e, também, sugere que a busca de uma ontologia do espaço corresponderia à "negação quase que total da dimensão real". Caberia notar que a associação entre ontologia e abstração idealista implica num juízo de caráter ontológico, pois provoca uma determinada forma de representar o que a ontologia é - no caso, "prisioneiro do mundo das ideias". Entretanto, a legitimidade da associação estabelecida pela autora não é, ela própria, objeto de investigação, constituindo, assim, um pressuposto de caráter ontológico, ele próprio não submetido a exame.

No mesmo sentido, cabe destacar que, para asseverar de modo tão contundente que a investigação acerca da natureza ontológica do espaço promoveria uma negação quase total da "dimensão real", (entenda-se, da "realidade") é imprescindível, por força da lógica, saber (ou pelo menos supor saber) o que a "realidade" é. Trata-se, assim, de um juízo de cunho ontológico, referido, no caso, à "dimensão real". Ou seja, a coerência da argumentação assumida pela autora incide, neces- 
sariamente, numa suposta compreensão do que é o real. Excluir, por exemplo, um modo de investigação, o ontológico, da "dimensão real" exige, antes de tudo, uma compreensão "verdadeira" do que é a "dimensão real" que permita, assim, excluir da "dimensão real" o que não corresponde à "dimensão real" - no caso, "a busca de uma ontologia do espaço". Ora, compreender o que algo é, no caso, a "dimensão real" é compreendê-lo em seu ser. É, portanto, uma compreensão que, ao menos formalmente, em nada transgride designá-la como "compreensão ontológica". A ambiguidade de uma posição que refuta a ontologia reside, assim, no fato de que a refutação não pode ser exercida sem proceder ontologicamente. Nesse sentido, a partir da reflexão aqui desenvolvida, inverte-se, radicalmente, a tese esposada acima, que defende a impossibilidade de elaborar uma ontologia do espaço: impossível seria, propriamente, existir teoria científica que pudesse prescindir de ontologia, na medi- da que ao se efetivar como investigação científica sobre "algo" libera, invariavelmente, uma compreensão acerca do que é investigado (seu objeto) em seu ser, isto é, fornece uma determinação sobre o que um objeto é6. A reflexão ontológica figuraria, assim, como um âmbito possível da elaboração teórica que se orientaria no sentido da prospecção dos pressupostos que sustentam a pesquisa científica, aspirando ao esclarecimento da pertinência, limites e radicalidade dos mesmos. Enquanto tal, isto é, enquanto possibilidade, constitui uma alternativa disponível ao exercício de teorização que pode - ou não - ser desenvolvida.

A despeito da diversidade de abordagens, significados e divergências acerca do tema "ontologia" na geografia, é possível reconhecer um enfoque tornado saliente pelo vulto que assumiu nessa disciplina. Trata-se da abordagem desenvolvida a reboque do mo-

\begin{tabular}{l}
\hline 6 Acerca da vigência da ontologia no seio da ciência a assertiva de \\
Heidegger é cabal "(...) toda ciência é fundamentada numa ontologia implícita
\end{tabular} de seu objeto". (HEIDEGGER, 2006: 161) 
vimento de renovação crítica-radical que a geografia conheceu, de modo substantivo, a partir da década de 1970, cujo traço fundamental incidiria na determinação (ou "entificação") social do "ser" do espaço (REIS, 2009). É nesse sentido que, não obstante dotado de uma perspectiva epistemológica pluralista (MOREIRA 2004b), é possível reconhecer no bojo do referido movimento a instauração de um projeto de uma ontologia social do espaço como um "viés" proeminente que a reflexão ontológica assumiu na teoria geografia e que se substantiva, fundamentalmente, pela determinação social do ser do espaço geográfico (REIS, 2009). Este viés de reflexão ontológica, desenvolvido por uma gama significada de teóricos que abordaram o assunto na geografia (SOJA, 1993; MORAES, 1982; SILVA, 1982; MOREIRA, 2004b) pode ser ilustrado de modo cabal na seguinte assertiva de Milton Santos: "Tudo, porém, tem início na realidade social, como escreveu Sebag (1972, p. 62): 'A pri- mazia do ser vem do fato de que ele jamais é acabado e essa inconclusão se resolve no tempo'. Se saímos da totalidade social é somente para tornar a ela. (...). O ser é a sociedade total, o tempo são os processos, e as funções, assim como as formas são a existência" (SANTOS, 1988, p. 27). Esta posição evidencia, em última instância, a força e - sobretudo - a posição decisiva que o pensamento de Marx possui na renovação crítica da geografia?. É, em igual medida, em função dessa matriz de estatuto ontológico que a noção de produção social do espaço será alçada ao cerne do debate teórico da geografia, sendo notadamente consagrada na esfera da reflexão acerca do objeto de uma geografia criticamente renovada (SANTOS, 1978[2008]).

Cabe, portanto - a despeito dos inequívocos avanços conquistados à teoria da geo-

7 A ontologia em Marx é assunto dilemático, assumindo posições as mais divergentes, que, não obstante, não inviabilizam a possibilidade de considerar a dimensão ontológica de seu pensamento (LOPARIC, 1990), a despeito, mesmo, das posições frontalmente refratárias acerca da reflexão em ontologia a partir do pensamento de Marx. 
grafia através da elaboração de uma ontologia de seu objeto assentada na noção de produção social do espaço - problematizar o significado desse viés de reflexão ontológica na geografia. É nesse sentido que o pensamento de Martin Heidegger é entrevisto como uma alternativa fecunda para ampliar o escopo da reflexão ontológica nesta vertente da teoria da geografia, na medida em que toda a sua obra é dedicada à questão ontológica primordial, a saber, a questão do ser (BLANC, 1998; LOPARIC, 1990). Mais precisamente, cabe considerar o significado da "onto-socio-logia"8 do espaço na geografia, focalizando o atributo que poderia ser apontado como mais fundamentalmente problemático segundo os parâmetros do pensamento de Heidegger, a saber: o problema da entificação do Ser ou, seu equivalente, a negligência para com o sentido da "diferença

8 "Onto-socio-logia" designa a determinação social que vigora na ontologia do espaço na geografia (REIS, 2009). O termo visa, também, sinalizar a vigência, no debate sobre o assunto na geografia, do "padrão" da ontologia tradicional enquanto "onto-teo-logia" no sentido imputado a essa noção por Heidegger. Ver, a respeito, Borheim (2001). ontológica", considerada o legado fundamental deste pensador (CRAIA, 2003) e que alinhava toda a trajetória de seu pensamento. O sentido "metodológico" da noção de diferença ontológica pode, de modo estritamente formal, ser sucintamente exposta nos seguintes termos: "O ser dos entes não "é" em si mesmo um outro ente. O primeiro passo filosófico na compreensão do problema do ser consiste em: não determinar a proveniência do ente como um ente, reconduzindo-o a um outro ente, como se o ser tivesse o caráter de um ente possível." (HEIDEGGER, 1999: 32). É patente a restrição que, a partir da citação acima, se coloca para uma parcela substantiva da reflexão ontológica na geografia, na qual se verifica a assimilação da sociedade (um ente) enquanto conteúdo quiiditativo com o qual se efetiva a determinação do ser do espaço, bem como do próprio ser. De fato, este problema permanece em suspenso para o viés da reflexão ontológica na geografia acima destacado, em função 
do caráter insidioso da determinação social do ser do espaço. A determinação social do ser do espaço acaba se impondo, sugere-se, um padrão auto-instituinte de fundamentação que, em boa parte da bibliografia corrente, não oferece, nos termos sob os quais é estabelecido, abertura para liberar outras possibilidades de elaboração ontológica acerca (do ser) do espaço.

É nesse sentido que se revela a relevância da questão da técnica em Heidegger para a reflexão ontológica, pois, tal como destacado por DUBOIS (2004:121) dentre as distintas modalidades (e fases) que a questão do ser assumiu na obra de Heidegger destaca-se a via em que seu pensamento converte-se numa "meditação histórica" dedicada a redimensionar a questão do Ser, reconduzindo-a a sua proveniência historial originária: a questão pela essência da técnica. Trata-se, como será visto mais adiante, de uma abordagem que contempla, de um modo que lhe é pró- prio, a possibilidade de preservar o sentido da diferença ontológica, isto é, entre ser e ente, como modo de resguardar a especificidade da abordagem temática do Ser de acordo com as coordenadas do pensamento do filósofo. No que interessa mais diretamente ao debate na geografia, a questão da técnica, tal como desenvolvida por Heidegger oferece essa alternativa, associando-a, além disso, a uma concepção da noção de produção dotada de significado radicalmente distinto da noção de produção social vigente da ontologia do espaço na geografia.

Tal como será evidenciado no que segue, o caráter inextrincável da relação entre produção, técnica e ser constitui o cerne do diálogo possível entre o pensamento de Heidegger e a reflexão ontológica na geografia, que, no presente trabalho irá focalizar a contribuição de Milton Santos (1996). A determinação social do ser vigente em parte significativa da reflexão sobre ontologia do espaço na geografia, 
acima indicada, encerra um exemplo patente de entificação do ser". Propriamente, a "entificação do ser" sinaliza o modo com o qual, em toda ontologia, se manifesta a "negligência" em relação à diferença ontológica entre ser e ente. Ressalte-se que, a rigor, as noções de "produção social do espaço" e "determinação social do ser do espaço" constituem expressões equivalentes no que diz respeito ao plano da reflexão ontológica sobre o espaço na geografia.

\section{ONTOLOGIA DO ESPAÇO, TÉCNICA E SER: O DIÁLOGO LATENTE ENTRE MILTON SANTOS E MARTIN HEIDEGGER}

9 Bornheim (2001) adverte sobre o risco de se considerar a "entificação do ser" em Heidegger a partir dos critérios tradicionais com os quais se consideram o "erro" e "verdade". Considerar que Hegel, "errou" porque determinou o ser a partir de um ente, embora encerre um juízo correto não revela o problema dentro das coordenadas da historicidade próprias ao pensamento deste filósofo: "aqui, o erro se torna errância histórica (p. 186)". Em trabalho precedente (REIS, 2009), o problema da entificação social do ser que se verifica em parcela significativa da reflexão ontológica na geografia foi mais detidamente desenvolvido, não obstante, de fato, tenha permanecido relativamente refém do "argumento de autoridade" sobre o assunto que Heidegger exprimiria, posto que para considerar, efetivamente, o significado restritivo da entificação do ser é necessário problematizá-la enquanto "errância histórica". Essa problematização, não obstante fundamental, excede as possibilidades do presente artigo, sendo necessário desenvolver essa reflexão numa outra oportunidade.
Na trajetória do pensamento teórico de Milton Santos sobre a natureza do espaço geográfico a assimilação da noção de técnica - bem como a abordagem explícita, isto é, temática, acerca da ontologia do espaço - assume importância crescente e decisiva ${ }^{10}$. Entrementes, será em seu livro A Natureza do Espaço. Técnica e Tempo, Razão e Emoção, - notadamente no capítulo As técnicas, o tempo e o espaço geográfico, que inicia a primeira parte do livro intitulada Uma ontologia do espaço: noções fundadoras - que a abordagem da técnica recebe o tratamento de cunho teórico-metodológico mais elaborado para a elaboração da ontologia do espaço na geografia.

Já na introdução do livro o geógrafo indica que sua abordagem da técnica se desdobra num tríplice aspecto: (i) revelar a produção histórica do real; (ii) inspirar um método \begin{tabular}{l}
\hline $10 \quad O$ recurso à noção de técnica no projeto de formulação teórica sobre \\
a natureza do espaço encaminhado por Milton Santos possui uma larga prove-
\end{tabular} niência (SANTOS, 2007:189 [1979]; 1988;89; 1994: 63 - 64). 
que afaste os dualismos "recorrentes" à geografia; (iii) ser apreendida desde uma perspectiva filosófica que permita considerar a técnica enquanto fenômeno técnico (SANTOS, 1996:20). Nestes três aspectos, compartidos pelo autor para fins analíticos de uma exposição panorâmica na introdução da obra, evidencia-se o traço marcante do recurso à noção da técnica no pensamento de Milton Santos: assimilar a repercussão da dimensão histórico-ontológica do fenômeno técnico sobre a esfera epistemológica da geografia. Corresponder, na linguagem conceitual, isto é, na esfera epistemológica, ao conteúdo técnico da produção do espaço converte-se, assim, desde que amparado por uma perspectiva suficientemente ampla, isto é, filosófica, numa tarefa entrevista pelo autor como necessária à teoria geográfica ${ }^{11}$.

\footnotetext{
11 A sensibilidade de Milton Santos à necessidade de uma abordagem
} de cunho filosófica como condição para apreender o fenômeno técnico de modo
Milton Santos atende, assim, ao reconhecimento da primazia fundacional da ontologia em relação a epistemologia no processo de construção teórica, primazia esta que encontra, efetivamente, pouco amparo na ciência geográfica e que pode ser expressa de maneira concisa nos seguintes termos:

\begin{abstract}
"Observe-se, de antemão, que são de teor ontológico as questões fundamentais acerca do estatuto das entidades teóricas do discurso científico e da organização interna do real. Por essa razão, só a ontologia pode fornecer uma autêntica fundamentação das ciências, sendo a investigação empírica por elas efetuada dirigida por modelos interpretativos e esquemas conceptuais, que pressupõem
\end{abstract}

suficiente coaduna com a perspectiva de Heidegger, para quem, tal como sublinhado por DUBOIS (2005:131) "é a filosofia que configura historicamente as relações essenciais com o ente. Relacionar-se essencialmente com o ente é a ele se ligar historicamente, pois as relações essenciais com o ente se dão como história da filosofia. Portanto, o verdadeiro nexo com a história é a própria filosofia, isto é, a meditação histórica, que deve se distinguir de toda consideração historiográfica". Ou, ainda: "A historiografia [ciência histórica], por seu lado, não determina, por ser ciência, a referência originária com a História, mas, ao contrário, sempre pressupõe tal referência. (...). Ora, de vez que somente na filosofia - à diferença de qualquer ciência - que se edificam sempre as referências essenciais com o ente, por isso essa referência pode, até deve ser para nós hoje uma referência originariamente Histórica"(HEIDEGGER, 1987: 70). 
uma determinada compreensão do ser e seus derivados". "Porque fornece, de per si, uma interpretação global do sentido do ser, seus modos e derivados, a ontologia é a única resposta adequada às questões, já referidas, do estatuto ontológico do discurso científico e da organização interna do ser do ente. A epistemologia, pelo contrário, na medida em que se propõe resolver aquelas questões a um nível meramente gnosiológico, só pode fornecer respostas aleatórias, já que necessariamente repousam numa decisão acerca do que em geral se entende por Ser, que em si mesma carece de uma justificação adequada". (BLANC, 1998:18 - 19).

Aspira-se, desta forma, na contribuição de Milton Santos, uma epistemologia da geografia cujo fundamento não seja estritamente tributário da esfera gnosiológica, isto é, restrita a uma construção intelectual assentada numa "lógica pura", mas, sobretudo, o autor aspira uma epistemologia que seja dotada, plena, pejada de historicidade. Enquanto designação do "ser" da história, a historicidade de todo e qualquer objeto dotado de conteúdo essencialmente histórico - notadamente, no caso, o espaço geográfico - torna-se acessível à ontologia na geografia através do recurso ao fenômeno técnico, pois,

"Na realidade, toda técnica é história embutida. Através dos objetos, a técnica é história no momento de sua criação e no de sua instalação e revela o encontro, em cada lugar, das condições históricas (econômicas, socioculturais, políticas, geográficas), que permitiriam a chegada desses objetos e presidiram à sua operação. A técnica é tempo congelado e revela uma história. (...). A técnica nos ajuda a historicizar, isto é, a produzir uma geografia como ciência histórica" (SANTOS, 1996:40).

A problematização da técnica na esfera da ontologia do espaço é considerada por este geógrafo como sendo crucial à fundamentação epistemológica da geografia, pois, para ele o "problema epistemológico propriamente dito da geografia (...) passa pelo encontro do caminho adequado para sistematizar as relações da técnica com o 'tempo" e com o 'espaço'" (SANTOS, 1996:40 - 41). É assim que o 
17 corregadia das relações entre espaço e tempo na geografia" (SANTOS, 1996:41).

Para apreender a técnica no âmbito da articulação de categorias ontológicas fundamentais à ontologia da geografia, tais como, dentre outras, o tempo e o espaço, o autor sublinha, desde as primeiras linhas da contribuição em tela, a necessidade de um enfoque abrangente da técnica, dado que,

"...a relação que se deve buscar, entre espaço e fenômeno técnico, é abrangente de todas as manifestações da técnicas, incluídas aí as técnicas da própria ação. Não se trata, pois, de apenas considerar as técnicas da produção, ou como outros preferem, as 'técnicas industriais', isto é, a técnica específica, vista como um meio de realizar este ou aquele resultado específico. (...). Só o fenômeno técnico na sua total abrangência permite alcançar a noção de espaço geográfico"(SANTOS, 1996:31).

Não é, absolutamente, por uma implicação exterior ao pensamento que Milton San- tos qualifica de filosófica a abordagem, por ele almejada, do fenômeno técnico. Trata-se, antes, do reconhecimento, por parte do autor, da constringência do tipo de pensamento necessário para corresponder à natureza da própria coisa a ser pensada - o que vale, a rigor, não só para a fundamentação da ontologia do espaço na geografia, mas para a ontologia no seio de qualquer ciência moderna. Esta demanda é tratada explicitamente pelo geógrafo:

\begin{abstract}
"Mediante um enfoque que leve em consideração e aperfeiçoe as premissas aqui delineadas, a geografia deve, ao menos, ser vista como um estudo de caso para as filosofias da técnica, senão propriamente como uma contribuição específica para a produção de uma filosofia das técnicas". (SANTOS, 1996:40).
\end{abstract}

O questionamento filosófico é aquele que, tradicionalmente, promove o pensamento acerca do ser, isto é - na linguagem metafísica - da "essência" daquilo que é questionado. Assim, ao seu modo - e na esfera de sua codi- 
ficação da linguagem teórica - quando, recorrentemente, Milton Santos argumenta que a abordagem da técnica deve, para ser suficiente, considerar o fenômeno técnico enquanto abrangente de todas as manifestações da técnica, não se restringindo, portanto, à técnica considerada isoladamente, aquilo que geógrafo tem efetivamente em vista - sob outra designação - é a essência da técnica. Ou melhor, o que o geógrafo tem em vista é estimular uma abordagem capaz de contemplar a "essência" da técnica. Para tanto o pensamento é, necessariamente, sempre e invariavelmente, um pensamento de ordem filosófica.

Desta maneira, para apreender, efetivamente, o sentido ontológico da técnica enquanto fenômeno técnico é indispensável formular a questão: o que é isto - a técnica? Coloca-se, agora, a necessidade de considerar o modo que o autor em tela trata, isto é, coloca e resolve essa questão crucial à ontologia do espaço assentada na noção da técnica.
Propriamente a reflexão de Milton Santos não apenas coloca a questão, pois, de fato, ela se desenvolve a partir de uma resolução muito determinada a respeito dela. Estritamente rigoroso com o propósito de fundamentação ontológica do espaço assentada na noção de técnica, o autor somente coloca em marcha sua reflexão a partir da explicitação da concepção de técnica que lhe dá sustentação. Isso é indicado, a propósito, nos dois parágrafos que abrem a reflexão da primeira parte do livro, nos seguintes termos:

"É por demais sabido que a principal forma de relação entre o homem e a natureza, ou melhor, entre o home e o meio, é dada pela técnica. As técnicas são um conjunto de meios instrumentais e sociais, com os quais o homem realiza sua vida, produz e, ao mesmo tempo, cria espaço. Essa forma de ver a técnica não é, toda via, completamente explorada" (SANTOS, 1996: 25).

É com base na concepção da técnica acima indicada que Milton Santos desenvolve sua 
ontologia do espaço. Coloca-se, desta forma, a necessidade de questionar o significado da concepção da técnica na ontologia do espaço em Milton Santos. Qual, portanto, a natureza da determinação da técnica na ontologia do espaço proposta por este autor? É a partir deste ponto, referente à concepção de técnica assumida por Milton Santos que o paralelo com a questão da técnica, tal como elaborada por Heidegger, torna-se fundamental.

No ensaio "A Questão da Técnica", o filósofo inicia sua reflexão interpelando diretamente o sentido da concepção de técnica esposada por Milton Santos, nos seguintes termos:

"A seguir, questionaremos a técnica. (...). "De acordo com uma antiga lição, a essência de alguma coisa é aquilo que ela é. Questionar a técnica significa, portanto, perguntar o que ela é. Todo mundo conhece ambas as respostas que respondem esta pergunta. Uma diz: técnica é meio para um fim. A outra diz: técnica é uma atividade do homem. Ambas as determinações da técnica pertencem reciprocamente uma à outra. (...).

A concepção corrente da técnica de ser ela uma meio e uma atividade humana pode se chamar, portanto, a determinação instrumental e antropológica da técnica" (HEIDEGGER, 2002:11, grifo nosso).

Do exposto, torna-se evidente que a concepção de técnica em Milton Santos corresponde ao modo com o qual, segundo o filósofo, a técnica é usualmente determinada, isto é, trata-se da concepção instrumental e antropológica da técnica. Revela-se, aqui, a base do paralelo que se propõe estabelecer entre os pensamentos do geógrafo do filósofo: a interpretação de Heidegger sobre o significado (e conseqüências) da determinação instrumental e antropológica da técnica serve para pensar o significado (e conseqüências) da concepção de técnica na qual está apoiada a ontologia do espaço proposta por Milton Santos.

O que Heidegger argumenta a respeito da determinação instrumental e antropológica da técnica? Qual o significado desta concepção corrente da técnica? Antes de tudo a concep- 
ção em tela não é, absolutamente, considerada como incorreta. Ao contrário, ressalta ele:

"Quem ousaria negar que ela é correta? Ela se rege evidentemente pelo que se tem diante dos olhos quando se fala em técnica. A determinação instrumental da técnica é mesmo tão extraordinariamente correta que vale até para a técnica moderna. Desta, de resto, afirma-se com certa razão ser algo completamente diverso e por isso novo face à técnica artesanal mais antiga. Também a usina de força, com suas turbinas e geradores, é um meio produzido pelo homem para um fim estabelecido pelo homem. Também o avião a jato, também a máquina de alta freqüência são meios para fins. Naturalmente, uma estação de radar é muito menos simples do que um cata-vento. [...] - Naturalmente, fabricar uma máquina de alta freqüência exige a integração de diversos processos de produção técnico-industrial. Permanece, portanto, correto: também a técnica moderna é meio para um fim" (HEIDEGGER, 2002:12).

A abordagem da técnica na ontologia do espaço proposta por Milton Santos permanece, portanto, estrita e rigorosamente correta. Qual, então, o aspecto a ser problematizado se a concepção instrumental e antropológica constitui um modo correto de representar a técnica?

Para o filósofo esta representação conduz, invariavelmente, todo o esforço - inclusive reflexivo - "para colocar o homem num relacionamento direito", isto é, acertado "com a técnica". Este impulso, associado à representação instrumental e antropológica da técnica, acaba por impedir que uma abordagem da técnica assim encaminhada alcance a finalidade a que se destina todo questionamento ontológico genuíno acerca de um ente, a saber: corresponder à essência do que é questionado. De acordo com o pensamento de Heidegger o questionamento ontológico sobre todo e qualquer ente, por exemplo, no caso, a questão "o que é isto - a técnica?" somente atinge o status de uma autêntica interpelação ontológica se promover um caminho capaz de alcançar aquilo que o ente é enquanto ente, isto é, a entidade do ente, ou, na tradição metafísica, sua "essência", enfim, o "Ser" do ente interpe- 
1 questionado é que se torna também acessível a verdade ${ }^{12}$ do ente questionado.

Desta forma, a determinação instrumental e antropológica da técnica, a despeito de seu caráter auto-evidente e do sentido teleológico elevado (colocar o homem numa relação acertada com a técnica) fornece uma representação da técnica que obstrui a possibilidade de corresponder à sua essência. Isso é válido para a técnica em qualquer época, seja a técnica antiga, artesanal ou a técnica moderna:

"Permanece, portanto, correto: também a técnica moderna é meio para um fim. É por isso que a concepção instrumental da técnica guia todo esforço para colocar o homem num relacionamento direito com a técnica. (...). Pretende-se dominar a técnica. (...).

"Supondo, no entanto, que a técnica não seja

12 O conceito de "verdade" em Heidegger resguarda, contudo, um sentido radicalmente distinto da representação habitual, seja no senso comum ou sob a lógica tradicional. um simples meio, como fica então a vontade de dominá-la? Dissemos acima que a determinação instrumental da técnica era correta. Com certeza. (...). Para ser correta, a constatação do certo e exato não precisa descobrir a essência do que se dá e apresenta. Ora, somente onde se der esse descobrir da essência, acontece o verdadeiro em sua propriedade. Assim, o simplesmente correto ainda não é o verdadeiro. E somente este nos leva a uma atitude livre com aquilo que, a partir de sua própria essência, nos concerne. Embora correta, a determinação instrumental da técnica não nos mostra a sua essência" (HEIDEGGER, 2002:13).

A restrição que o filósofo atribui à determinação instrumental da técnica para uma reflexão ontológica que aspire corresponder a sua essência é cabal, pois, para ele "enquanto representarmos a técnica, como instrumento, ficaremos presos à vontade de querer dominá-la. Todo nosso empenho passará por fora da essência da técnica" (HEIDEGGER, 2002:35). Do exposto revela-se uma forte restrição à concepção de técnica que sustenta a ontologia do espaço em Milton Santos: porquanto tributária de uma concepção instrumental e antro- 
22 putada à concepção da técnica acima indicada não se esgota como algo exclusivamente negativo, na medida em que, embora não seja considerada pelo filósofo, de fato, como uma concepção por si só suficiente para corresponder à essência da técnica, ela é, doravante, imprescindível, pois,

"Para chegarmos à essência [da técnica] ou ao menos em sua vizinhança, temos de procurar o verdadeiro através e por dentro do correto. Devemos, pois, perguntar: o que é o instrumental em si mesmo? A que pertence meio e fim? Um meio é aquilo pelo que se faz e obtém alguma coisa. Chama-se causa o que tem como conseqüência um efeito. (...). Onde se perseguem fins, aplicam-se meios, onde reina a instrumentalidade, aí também impera a causalidade" (HEIDEGGER, 2002:35).

De acordo com o pensamento em tela a apreensão da essência da técnica exige, preliminarmente, que o sentido da determinação instrumental da técnica como instrumento do homem seja explicitada em seus fundamentos, o que implica desenvolver uma interpretação suficientemente ampla da própria essência do instrumento, isto é, da instrumentalidade. Para tanto Heidegger assume um caminho que se desdobra em duas frentes, não obstante complementares, que tem na experiência originária do logos grego o ponto de convergência. Trata-se, por um lado, de compreender o significado da concepção instrumental da técnica através da tematização da instrumentalidade em si mesma, o que remete à concepção grega da causalidade deduzida da teoria aristotélica das quatro causas; e, por outro lado, considerar o âmbito do sentido originário da palavra técnica na palavra grega téxvn (technè).

Para explicitar o sentido da instrumentalidade do instrumento que remete ao princípio da causalidade Heidegger lança mão da doutrina aristotélica das quatro causas (causa materialis, causa formalis, causa finalis e a causa 
33 intrínseca às quatro causas. Em síntese o filósofo indica que as quatro causas respondem pelo dar-se e pro-por-se do que se produz, no caso, o cálice. As palavras Dar-se e propor-se evocam, na experiência do pensamento grego, a vigência do que está em vigor enquanto um deixar-viger. Isto é, as quatro causas, na co-pertinência da relação intrínseca entre elas, deixam, cada uma a seu modo, que algo - um ente - que, por si mesmo, ainda não vige, venha a viger em seu pleno advento. As quatro causas tornam presente entes que, por si próprios, não estariam presentes. As quatro causas conduzem o deixar-viger numa condução (ou, na acepção moderna, "num processo") que conduz o vigente a aparecer. Portanto, é essa condução que encerra o elemento próprio da experiência grega plantada na "palavra/expressão" deixar-viger. Heidegger recorre, nesse ponto de sua reflexão, a uma sentença seminal do Banquete de Platão:

"Todo deixar-viger o que passa e procede do não-vigente para a vigência é noinoıৎ (poiésis), é produção".

A partir desse ponto a almejada proximidade à essência da técnica torna-se função da amplitude com a qual se pode fazer a experiência de pensar a pro-dução numa correspondência ao sentido originariamente grego. Para Heidegger, no âmbito desta experiência originária de pensamento, pro-dução é o advento capaz de conduzir algo do encobrimento ao des-encobrimento. Somente quando alguma coisa velada é des-velada que a pro-dução se dá propriamente. $\mathrm{Na}$ experiência grega, o des-encobrimento era nomeado na palavra à $\lambda$ ṅ $\theta \varepsilon ı$ (a-lethéia), traduzido na experiência do pensamento romano pela palavra veritas e na modernidade por "verdade", para designar, então, uma representação correta em que se verifica a adequação do intelecto à coisa.

Desta forma, no percurso de pensamen- 
to de Heidegger, o questionamento acerca da concepção instrumental da técnica revela que, em sua essência, a técnica pertence ao âmbito do dês-encobrimento, isto é, da verdade, que encerra a condição de possibilidade de toda e qualquer atividade produtiva (instrumental). Por conseguinte revela-se que, em seu fundo essencial,

"A técnica não é, portanto, um simples meio. A técnica é uma forma de desencobrimento. Levando isso em conta, abre-se diante de nós todo um outro âmbito para a essência da técnica. Trata-se do âmbito do desencobrimento, isto é, da verdade. (HEIDEGGER, 2002:17).

Por sua vez, a consideração acerca do sentido originário da palavra "técnica", isto é, de sua proveniência historial referida ao mundo grego constitui outro viés com o qual o filósofo ratifica o sentido da técnica enquanto modo de des-encobrimento, isto é, da pro-dução enquanto poiésis, verdade, no sentido acima referido. A palavra TÉxvn (técnica), tal como indica Heidegger, está em sua origem grega intimamente relacionada com a palavra

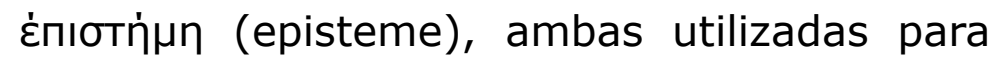
designar o conhecimento em seu sentido mais abrangente. O filósofo indica, aqui, a estreita relação entre conhecimento e "abertura", compreendida como acesso ao real: o conhecimento é, na esfera do pensamento grego, uma experiência que promove abertura, isto é, des-encobrimento. Nesse ponto Heidegger recor-

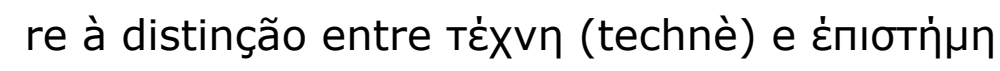
(episteme) estabelecida por Aristóteles na

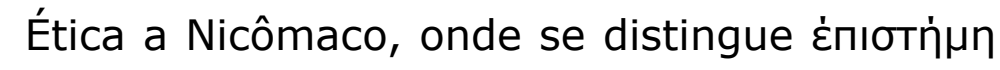
(episteme) de T⿱亠乂⿰丿丨 (técnica) enfatizando a especificidade com a qual cada palavra configura um tipo de des-encobrimento próprio - a

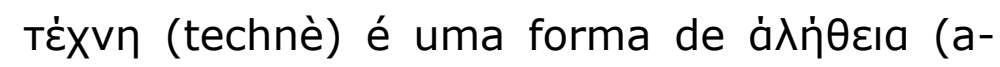
-lethéia), de des-encobrimento, cuja especificidade reside em que ela dês-encobre o que não produz a si mesmo.

Do exposto, resume-se: tanto a investigação sobre a instrumentalidade do instrumento, 
25 de Heidegger, qual seja, a técnica não é um simples meio, mas, fundamentalmente, uma forma de dês-encobrimento! Por conseguinte, "o decisivo da téxvn não reside pois no fazer (na dimensão instrumental), nem na aplicação de meios - mas, decisivamente, no desencobrimento mencionado (HEIDEGGER, 2002: 18).

Assim, ratifica-se - a técnica não é um simples meio. Ela é um lócus, uma dimensão, que torna possível o dês-encobrimento, o "acesso" ao real. Além disso, de acordo com seu sentido originário - do qual toda representação moderna permanece tributária de maneira precária "A Téxvn pertence à pro-dução, a poiésis, é, portanto, algo poético" ( HEIDEGGER, 2002: 17).

A associação entre técnica e produção com algo poético é, por mais atípico que possa parecer à representação moderna, funda- mental no pensamento de Heidegger sobre a essência da técnica. De fato, sob a representação corrente, tudo favorece a rejeição da idéia de que a técnica, sobremaneira no modo que ela se dá no mundo moderno, possa ser associada com algo poético. Um paralelo dessa ordem pode ser válido, no máximo, na experiência originária da palavra "técnica" no mundo grego antigo, portanto, num "outro mundo" que não o mundo moderno e da técnica que Ihe é correspondente.

A objeção acima é, de fato, válida para a representação moderna-epigonal dominante, tanto para técnica moderna quanto para o "poético", mas é imprópria para o âmbito do pensamento de Heidegger sobre a essência da técnica. Trata-se mesmo de um atributo central no pensamento tardio deste filósofo revelar que mesmo a técnica moderna é, ao seu modo próprio, uma forma específica de des-encobrimento no sentido já referido, qual seja, de des-encobrimento do real, de abertu- 
ra, isto é, do modo de relação e pertencimento do homem à verdade. Coloca-se, então, moderna enquanto um modo de des-encobrimento? Resposta de Heidegger: A técnica moderna constitui um modo próprio de des-encobrimento, cuja especificidade reside em dis-por o real à exploração, isto é, à interpelação produtora-exploradora da totalidade do ente. Enquanto tal, a técnica moderna configura uma variação historial do des-encobrimento da produção poiética originária, tal como se deu originariamente na eclosão essencial do "mundo grego". Trata-se de um tipo específico de des-encobrimento que promove uma espécie de pro-ducção, isto é, um tipo de "poiésis", por assim dizer, "epigonal", qual seja, o des-encobrimento explorador.

A concepção instrumental e antropológica da técnica e a constituição do homem em sujeito e do mundo em objeto são conseqüências dessa forma de des-encobrimento do real, não sua causa. A extensão do que está em jogo no pensamento de Heidegger e que é aqui particularmente direcionado à ontologia da geografia constitui um desafio de pensamento cuja envergadura é amplíssima, pois envolve o modo de representação do real que o pensamento ocidental assumiu na modernidade, do qual, na condição de ciência moderna, a geografia é tributária ${ }^{13}$.

Sob a regência da técnica moderna a totalidade dos entes é "arrastada" ao des-encobrimento explorador da interpelação produtora. A natureza, o mundo, o próprio homem, enfim, a totalidade dos entes, está, na época da técnica moderna, submetidos ao poder explorador da técnica moderna. Num sentido amplo, é o poder da essência da técnica moderna que, sob o modo do des-encobrimento explorador, "coloca", isto é, dis-põe o real sob sua regência (HEIDEGGER, 2002). Mas o que sig13 "..., a transformação do homem em sujeito e do mundo em objeto é
uma conseqüência do estabelecimento da essência da técnica, e não o contrário". (HEIDEGGER, 2002:334) 
nifica esse poder? De onde ele provém? Quais seus desdobramentos fundamentais? Como o questionamentos é necessário destacar duas noções centrais à elaboração da questão técnica em Heidegger, quais sejam, a disponibilidade (Bestand) e a com-posição (Gestell).

Com a palavra dis-ponibilidade o autor estabelece uma categoria para designar "o modo em que vigora tudo que o desencobrimento explorador atingiu" (HEIDEGGER, 2002:21). Sob a técnica moderna todo e qualquer ente particular se dis-põe ao homem enquanto dis-ponibilidade. A dis-ponibilidade perfaz, assim, a qualidade de tudo aquilo que se torna dis-ponível ao poder de exploração da técnica moderna, o quê abarca, conforme observado, a totalidade dos entes. A disponibilidade não é, contudo, a essência da técnica moderna, mas uma decorrência do poder dessa essência que instaura o des-encobrimento explorador. Para tanto, isto é, para designar o poder da essência da técnica moderna o filósofo emprega a palavra Gestell, traduzida por com-posição.

O que é com-posição, o Gestell? Esta é uma noção-chave para a questão da técnica em Heidegger, pois é através dela que é considerada não somente a caracterização da essência da técnica moderna, mas também o tipo de relação que o homem estabelece com esse poder. O que segue é uma exposição condensada e parcial dos traços básicos da caracterização da com-posição empregada pelo pensador alemão para designar o poder da essência da técnica moderna. A noção em tela resguarda o núcleo fundamental da des-antropologização da técnica que, no pensamento de Heidegger conduz à transfiguração da figura do homem como sujeito e do "real" como objeto.

Para Heidegger a essência da técnica se dá na com-posição, enquanto a força de reunião do "por" que "impõe ao homem des-cobrir o real como dis-ponibilidade". Enquanto essên- 
28 isto é, algo que se dê exclusivamente a partir do homem. Não sendo algo produzido pelo homem, como este se relaciona com a com-posição? De acordo com o pensamento em tela, o des-encobrimento do "real" enquanto disponibilidade não pode se manifestar sem $o$ homem. Contudo, o poder que conduz ao des-encobrimento do real como dis-ponibilidade, isto é, a com-posição, não se dá - de acordo com o pensamento de Heidegger - apenas pelo comportamento volitivo do homem. Este é requisitado, interpelado, provocado, de modo único, no seio da totalidade dos entes, a participar da com-posição como o poder que manifesta todo o real como disponibilidade. A com-posição é a essência da técnica moderna. Contudo, a com-posição não é pensada pelo filósofo como essência no sentido de gênero que reúne, numa universalidade formal, a unidade da diversidade de todas as manifes- tações da técnica moderna. A proposta "heideggeriana" de pensar a essência da técnica enquanto com-posição requer um modo alternativo à lógica tradicional-metafísica de pensar o significado da própria essência. Na esfera deste pensamento a com-posição é essência da técnica pensada enquanto um envio historial do destino do des-velamento do Ser. Essa forma de repensar a concepção de "essência", através da investigação da essência da técnica é sobremodo relevante para ratificar o caráter não-antropológico da com-posição, ou seja, revelar que o des-encobrimento do real enquanto dis-ponibilidade se destina ao homem moderno mas não é, absolutamente, um produto somente humano ${ }^{14}$.

Antes de tudo convém frisar que o destino não é pensado pelo filósofo sob a conotação de uma fatalidade esotérica, mas uma noção que visa resguardar a correlação entre 14 É digno de nota que, não obstante restrito à representação instrumental e antropológica da técnica Milton Santos evoque, conforme visto anteriormente, a técnica como fenômeno em que o humano e o não-humano são inseparáveis. 
a história (Geschichte) com aquilo que é destinado (Geschicklich) pelo Ser. O destino signide reunião encaminhadora, que põe o homem a caminho de um [tipo de] des-encobrimento" (HEIDEGGER, 2002:27). Todo modo de des-encobrimento do Ser possui uma proveniência historial enquanto envio do destino e, assim, também a com-posição, enquanto envio destinado do poder da essência da técnica moderna,

\begin{abstract}
"Deve também fazer ressoar o eco de um outro 'por' de onde ele provém, a saber, daquele pro-por e ex-por que, no sentido da poiésis, faz o real vigente emergir para o desencobrimento. Este propor produtivo [poiético] e o dis-por da exploração, na acepção aqui pensada, são, sem dúvida, fundamentalmente diferentes e, não obstante, preservam, de fato, um parentesco de essência. Ambos são modos de desencobrimento, modos de alethéia. Na com-posição, dá-se com propriedade aquele desencobrimento em cuja consonância o trabalho da técnica moderna des-encobre o real, como dis-ponibilidade" (HEIDEGGER, 2002:24).
\end{abstract}

O recurso à noção de "diagramas epocais" pode auxiliar na interpretação da com-posição enquanto envio do destino historial do des-velamento do Ser. De acordo com a interpretação de CRAIA (2003:73), no pensamento de Heidegger, a essência da técnica moderna, isto é, a com-posição, encerra, enquanto envio do destino da história ocidental-européia, um "diagrama epocal do des-ocultamento do Ser". Os "diagramas epocais" configuram diferentes modos - históricos - do Ser se manifestar. São, assim, períodos nos quais surge e se desencadeia um determinado tipo de des-ocultamento do Ser, e um correspondente tipo de des-velamento do mundo ôntico que vigora até seu desaparecimento sob a eclosão de um outro modo de des-ocultamento do Ser. Os "diagramas epocais" correspondem, portanto, ao plano ontológico sob os quais se manifestam diferentes épocas. Embora enviados ao homem, embora requisitem o homem, os diagramas epocais, porquanto encerrem en- 
vios históricos destinados de des-ocultamento do Ser, não são, em si mesmos, produzidos pelo homem.

A partir do exposto torna-se mais claro o sentido de "essência" que Heidegger imputa à noção de com-posição para designar a essência da técnica moderna como envio de um destino historial. Revela, outrossim, o perfil da participação do homem no âmbito da com-posição:

"Quem realiza a exploração que dês-encobre o chamado real, como disponibilidade? Evidentemente, o homem. Em que medida o homem tem este des-cobrir em seu poder? O homem pode, certamente, representar, elaborar ou realizar qualquer coisa, desta ou daquela maneira. O homem não tem, contudo, em seu poder o desencobrimento em que o real a cada vez se mostra ou se retrai e se esconde". (...).

"Somente à medida que o homem já foi desafiado a explorar as energias da natureza é que se pode dar e acontecer o desencobrimento da dis-posição [exploradora]. Se o homem é, porém, desafiado e disposto, não será, então, que mais originariamente do que a natureza, ele, o homem, pertence à disponibilidade? (...)

"Todavia, precisamente por se achar desafiado a dis-por-se de modo mais originário do que as energias da natureza, o homem nunca se reduz a uma mera dis-ponibilidade. Realizando a técnica [ mesmo no sentido instrumental] o homem participa da dis-posição, como um modo de des-encobrimento[da exploração]. O des-encobrimento em si mesmo, onde se desenvolve a disposição [da exploração], nunca é, porém, um feito do homem (HEIDEGGER, 2002 :21-22).

A maneira que o homem integra a com-posição sinaliza, para Heidegger, a ambiguidade fundamental do poder da essência da técnica moderna para o homem. Esta ambigüidade diz respeito à com-posição como um poder que representa tanto o perigo extremo quanto, em igual medida, a força salvadora da humanidade do homem. Pensar o significado da com-posição requer que se pense a articulação - intrínseca à essência da técnica moderna - entre o perigo extremo, a força do que salva e a essência do homem.

Em que medida o filósofo considera o 
31 acordo com seu pensamento, sob o poder da com-posição o homem assume tudo, inclusive a si próprio, como disponibilidade. Mas isso não é tudo: o império da com-posição encobre todo e qualquer modo de des-encobrimento e, sobretudo, a si mesmo como um modo de des-encobrimento. Assim,

"A com-posição não põe, contudo, em perigo apenas o homem em sua relação consigo mesmo e com tudo que é está sendo. Como destino, a com-posição remete ao desencobrimento do tipo da dis-posição [exploradora]. Onde esta domina, afasta-se qualquer outra possibilidade de desencobrimento. A com-posição encobre, sobretudo, o desencobrimento, que, no sentido da [poiésis], deixa o real emergir para aparecer em seu ser. Ao invés, o pôr da ex-ploração impele à referência contrária com o que é e está sendo. Onde reina a com-posição, é o direcionamento e asseguramento da disponibilidade que marcam todo o desencobrimento. Já não deixam surgir e aparecer o desencobrimento em si mesmo, traço essencial da dis-ponibilidade.

Assim, pois, a com-posição provocadora da ex- ploração não encobre apenas um modo anterior de desencobrimento, a pro-dução [no sentido da poiésis], mas também o próprio encobrimento, como tal, e, com ele, o espaço, onde acontece, em sua propriedade o desencobrimento, isto é, a verdade"(HEIDEGGER, 2002:30).

É no sentido acima indicado, qual seja, de poder encobrir o próprio des-encobrimento, que o filósofo observa na com-posição o perigo extremo que a essência da técnica moderna representa ao homem. Do exposto a ameaça que a técnica moderna representa não advém, fundamentalmente, da dimensão instrumental da técnica, isto é, do uso eventualmente "malévolo" de máquinas e equipamentos técnicos modernos, mas diz respeito à repercussão do poder da essência da técnica sobre o modo com o qual o homem tem acesso ao real. $\mathrm{O}$ perigo extremo assenta-se, assim, no poder que a essência da técnica manifesta de restringir o homem à dis-ponibilidade como único modo de des-encobrimento que dissimula a si mes- 


\section{2 ao homem a possibilidade de voltar-se para} um modo de des-encobrimento que permita resguardar a dignidade de sua essência humana - qual seja: sua relação histórica com o Ser.

Por sua vez, para o pensador a com-posição vela, ao mesmo tempo, o que salva. Isso se dá na medida em que, no esforço de pensar a essência da técnica, apreendemos a com-posição como destino de um des-encobrimento e, assim, já nos movemos num regime de pensamento que inspira um forte apelo de libertação. Este apelo segue um caminho de pensamento radicalmente outro daquele que está condicionado a favorecer exclusivamente a dis-ponibilidade exploradora e dela retira todos os seus parâmetros. Nesse sentido, pensar a com-posição em sua radicalidade não abre apenas uma alternativa de des-velamento do real, mas abre, fundamentalmente, a abertura enquanto abertura, isto é, o âmbito do aberto - como foi visto, da a-lethéia, da verdade. A relação originária com o des-encobrimento, isto é, com o Ser, é o que salva a humanidade do homem. Assim, pensando o poder da essência da técnica o homem pensa, necessariamente, o des-encobrimento e compreende, também, a com-posição como um modo historial específico de des-encobrimento. A tarefa de pensar a com-posição revela que o des-encobrimento (do Ser) não pode prescindir de requisitar o homem, tanto quanto este também carece do des-encobrimento para se relacionar, de acordo com sua essência, com a realidade.

Assim o homem se encontra apropriado, em sua essência, pela apropriação do des-encobrimento, isto é, pela apropriação da verdade. A apropriação do homem ao des-encobrimento é o que salva, na medida em que conduz o homem a ingressar naquilo que, para o filósofo, significa a dimensão mais elevada da dignidade da essência do homem, da hu- 
manidade do homem, qual seja: a vigília protetora, neste mundo, da abertura ao des-encobrimento e do mistério de seu encobrimento (HEIDEGGER, 2002).

Com base no percurso do questionamento da técnica aqui conduzido, cabe reestabelecer mais diretamente, ainda que de modo breve e a guisa de considerações finais, a referência ao plano da fundamentação ontológica do espaço na geografia.

\section{CONSIDERAÇÕES FINAIS}

O presente texto trouxe à tona o tema da ontologia do espaço na geografia e propôs problematizá-lo, basicamente, desde as possibilidades que a perspectiva de elaboração a partir da noção de técnica oferece ao debate teórico. A reflexão foi orientada no sentido de por em relevo o paralelo entre, por um lado, o viés proposto por Milton Santos de elaborar uma ontologia do espaço centrada em torno da no- ção de técnica e, por outro lado, a abordagem ontológica da técnica em Martin Heidegger.

A relação intrínseca entre técnica, produção e ser constitui o elo que alinhava o diálogo possível entre uma perspectiva de reflexão ontológica na geografia - representada no presente trabalho através do recurso à obra de Milton Santos - e o pensamento de Heidegger. A reflexão partiu, assim, da problematização da determinação social do ser vigente em parcela expressiva da reflexão sobre ontologia do espaço na geografia, compreendendo essa perspectiva como um exemplo crasso de entificação do ser. Sob esse viés, porquanto socialmente (pré) determinada, a produção em geral e a produção do espaço em particular, serão sempre - e irremediavelmente - produção social. Sob esse ângulo de consideração torna-se inacessível a possibilidade de, sequer, elaborar uma pergunta mais originária, que deveria, enquanto tal, ser previamente considerada para "fundamentar" a adjetivação so- 
34 sionar essa questão cuja proposta de investigação é, sem dúvida, "extra-vagante" para a representação habitual sobre o assunto na teoria da geografia. Ela não pode, efetivamente, ser desenvolvida a partir dos parâmetros "consagrados" pela vertente da geografia acima indicada, na medida em que nesse contexto a referida questão é considerada, antes de tudo, supérflua como questão, posto que referida a um pressuposto autoevidente, qual seja: produção é produção social! Pelo mesmo motivo a relação eventual entre produção e Ser (isto é, entre produção e ontologia) não precisa ser necessariamente conjecturada, podendo até mesmo ser rejeitada (CARLOS, 2011). Ora, através da abordagem ontológica desenvolvida no presente texto, para que seja possível assumir a "sociedade" (ou as diversas modalidades de seus equivalentes conceituais: reprodução das relações sociais de produção; reprodução social; etc.) como o conteúdo através do qual se determina a produção, não seria necessário preliminarmente (re) colocar a questão "O que é Produção?" e, sobretudo, desenvolver a questão, isto é, efetivamente investigá-la como algo digno de ser questionado? O presente texto não se propôs a desenvolver, ele próprio, desmesurada tarefa. Contudo, trouxe à tona uma perspectiva de problematização ontológica que não deixa de contribuir no sentido de provocar o problema lançado. Isso se verifica pelo recurso de uma "concepção" alternativa acerca da produção a partir do pensamento de Heidegger, compreendo que a existência de uma "concepção" de produção alternativa já represente, por ela própria, de algum modo, um auxílio no sentido de ponderar a legitimidade e procedência intelectual de se colocar sob outra perspectiva a questão "O que é produção?" na medida em que atesta, afinal, outra possibilidade de pensar a produção sob um ângulo "alternativo" 


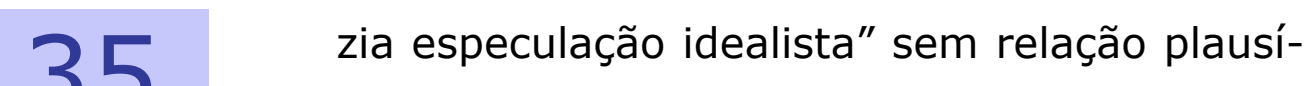

àquele consagrado pela determinação social

e que, por sua vez, não incida em uma "vavel com "a" realidade (histórica) da produção. Cabe, assim, questionar: a relação entre produção e Ser constitui uma relação necessária ou facultativa? A propósito dessa questão caberia, por fim, indicar que uma perspectiva de desdobrá-la, a partir da reflexão ontológica na geografia, implicaria um pensamento que concedesse legitimidade para se encaminhar em direção a uma concepção da produção do espaço como composição. 


\section{Referências Bibliográficas}

BESSE, J-M. Geografia e Existência: A Partir da Obra de Eric Dardel. In: O Homem e a Terra. DARDEL, E. São Paulo: Editora Perspectiva S.A, 2011. P. 111-139.

BITETI, M. de. O. Uma Reflexão Sobre o Tema da Ontologia na Geografia. 2007. 147p. Dissertação em Geografia. PosGeo - UFF.

BLANC, M de Faria. Estudos Sobre o Ser. Lisboa: Fundação Calouste Gulbekian, 1998.

BORNHEIM, G. Metafísica e Finitude. São Paulo: Editora Perspectiva S.A, 2001.

CARLOS, A. F. A. A Condição Espacial. São Paulo: Editora Contexto, 2011.

CHANSIN, J. Marx: Estatuto Ontológico e Resoluções Metodológicas. São Paulo: Boitempo Editorial, 2009 (1995).

CORRÊA, R. L. Espaço: um conceito-chave da Geografia. In: Castro, I. E. et alli: Geografia: Conceitos e Temas. Rio de Janeiro: Editora Bertrand Brasil, 1995.

CRAIA, E. C. P. Gilles Deleuze e a Questão da Técnica. Tese de Doutorado. UNICAMP. Campinas, 2003.

DUBOIS, C. Heidegger: Introdução a uma leitura. Rio de Janeiro: Editora Jorge Zahar, 2005.

HEIDEGGER, M. A Questão da Técnica. in: Ensaios e Conferências. Rio de Janeiro: Editora Vozes, 2002[1954].

2002[1977].

. Para quê poetas? In: Caminhos da Floresta. Lisboa: Fundação Calouste Gulbenkian, . Ser e Tempo. Rio de Janeiro: Editora Vozes, 1988.

UNIJUÍ, 2002.

. O Enigma da Sociedade Industrial. In: STEIN, E. Filosofia. Rio Grande do Sul: Editora 
HOLZER, W. A Construção de Uma Outra Ontologia Geográfica: A Contribuição de Heidegger. In: Geografia. Rio Claro - SP: Associação de Geografia Teorética, v. 35, n.2, 2010. P. 241-251.

pectiva S.A, 2011. P. 141-153.

. Mundo e Lugar: Ensaio de Geografia Fenomenológica. In: Qual o Espaço do Lugar? (Org.) MARANDOLA JR, E; HOLZER, W; OLIVEIRA, L. de. São Paulo: Editora Perspectiva S.A, 2012. P. 281-304. LESSA, S. Para Compreender a Ontologia de Lukács. Ijuí - RS: Editora Ijuí, 2007 (1996).

LOPARIC, Z. Heidegger Réu (um ensaio sobre a periculosidade da filosofia). São Paulo: Editora Papirus, 1990.

LUKÁCS, G. A Ontologia do Ser Social. Os Princípios Ontológicos Fundamentais de Marx. São Paulo: Livraria Editora Ciências Humanas, 1979a.

MARANDOLA JR, E. Heidegger e o Pensamento Fenomenológico em Geografia: Sobre o Modos Geográficos de Existência. Geografia. Rio Claro - SP (Texto Aprovado Para Publicação), 2011, S/P.

. Lugar Enquanto Circunstancialidade. In: Qual o Espaço do Lugar? (Org.) MARANDOLA JR, E;

HOLZER, W; OLIVEIRA, L. de. São Paulo: Editora Perspectiva S.A, 2012. P. 227-247.

MORAES, A. C. R. Em Busca da Ontologia do Espaço. In: Moreira, R. (org.) Geografia: Teoria e Crítica. Rio de Janeiro: Editora Vozes, 1982.

MOREIRA, R. Realidade e Metafísica nas Estruturas Geográficas Contemporâneas, in: Redescobrindo o Brasil 500 Anos Depois. P. 341 - 360, Rio de Janeiro: Bertrand Brasil, 1998.

. A Diferença e a Geografia. O ardil da identidade e a representação da diferença na Geografia. GEOgraphia. Ano I, no. 1. Niterói: PPGEO-UFF, 1999.

. Marxismo e geografia: a geograficidade e o diálogo das ontologias. GEOgraphia. Ano VI, 
no. 11. Niterói: PPGEO-UFF, 2004b.

. Para onde vai o pensamento geográfico? São Paulo: Editora Contexto, 2006.

38 . O Espaço e o contra-espaço: as dimensões territoriais da sociedade civil e do Estado, do privado e do público na ordem espacial burguesa. In: Território, territórios (ensaios sobre o ordenamento territorial). Rio de Janeiro: Editora Lamparina, 2007[2002].

. Pensar e Ser em Geografia. São Paulo: Editora Contexto, 2007.

. O Pensamento Geográfico Brasileiro. As matrizes clássicas originárias. São Paulo : Editora Contexto, 2008.

. Geografia e Práxis - a Presença do Espaço na Teoria e na Prática Geográficas. São Paulo: Editora Contexto, 2012.

PEDROSA, B. V. A Geografia Crítica Brasileira e o Debate Sobre Ontologia do Espaço: Uma Aproximação. Vitória - ES: Revista Geografares, no 11, 2012. P. 139-168.

Acessado em: http://www.periodicos.ufes.br/geografares/issue/view/253/showToc.

RÉE, J. Heidegger. São Paulo: Editora Unesp, 1999.

REIS, L. C. T. Ontologia do espaço e movimento de renovação crítica da Geografia: o desafio da diferença ontológica. Geografares. No 7. Vitória-UFES, 2009.

SANTOS, M. A Totalidade do Diabo: como as formas geográficas difundem o capital e mudam as estruturas sociais. In: Economia Espacial. São Paulo: Edusp, 2007[1979].

Técnica, Espaço e Tempo (Globalização e meio técnico-científico-informacional. São Paulo:

HUCITEC, 1994.

. A Natureza do Espaço. Técnica e tempo, razão e emoção. São Paulo: HUCITEC, 1996.

. Metamorfoses do Espaço Habitado. São Paulo: HUCITEC, 1998. 
SILVA, A. C. da. O Espaço como Ser: uma auto-avaliação crítica. In: Geografia: Teoria e Crítica. Moreira, R. (org). Rio de Janeiro: Editora Vozes, 1982.

. As Categorias Como Fundamentos do Conhecimento Geográfico. In: Seminário "Filosofia e Geografia". Rio de Janeiro: AGB-Rio, 1993.

SOJA, E. W. Geografias Pós-Modernas. A reafirmação do espaço na teoria social crítica. Rio de Janeiro: Jorge Zahar Editores, 1993 (1985). 